\title{
Mean Platelet Volume and Red Cell Distribution Width Values in Patients with COVID-19 Admitted to Intensive Care Units or Wards from Emergency Department
}

\author{
Mehmet Ali Ceyhan $^{1}$ (D) \\ Miray Tümer² (D) \\ Gültekin Kadi² \\ Gültekin Günhan Demir ${ }^{3}$ (D) \\ 1 Health Sciences University, Ankara City Hospital, Department of Emergency Medicine, Ankara, Turkey
2 Ankara City Hospital, Department of Emergency Medicine, Ankara, Turkey
3 Istanbul Medipol University Medical Faculty, Department of Cardiology, Istanbul, Turkey
}

Selahattin Gürü²

\begin{abstract}
Background: Mean platelet volume (MPV) and red cell distribution width (RDW) values are components of complete blood count (CBC) which is a routine, cheap and fast test used in the evaluation of patients admitted to the emergency department (ED). The present study aimed to investigate RDW and MPV values in patients with Novel Coronavirus Disease 2019 (COVID-19) admitted to intensive care units (ICU) or wards from the ED.
\end{abstract}

Methods: A retrospective data analysis of patients who were admitted to Ankara City Hospital ICUs and wards with the diagnosis of COVID-19 was performed. Group 1 included patients admitted to ICUs and Group 2 included those admitted to wards.

Results: A total of 127 patients were admitted with a COVID-19 diagnosis. Mean age in Group 1 and Group 2 were $46 \pm 17$ and $41 \pm 14$, respectively. The number of patients admitted to ICU (Group 1) was $46(36.2 \%)$, and the number of patients admitted to wards (Group 2) was $81(63.7 \%)$. Of all patients, 122 patients $(96.06 \%)$ were discharged and 5 patients (3.9\%) died. RDW values in Group 1 was higher than those in Group 2 ( $\mathrm{p}<0,001)$. Similarly, MPV was higher in Group 1 than Group 2 ( $\mathrm{p}<0,001)$.

Conclusion: In patients with COVID-19, RDW and MPV values are higher in those admitted to ICU than patients admitted to wards from the ED.

Key words: Complete Blood Count, COVID-19, Mean Platelet Volume, Intensive Care Units, Red Cell Distribution Width. 


\section{INTRODUCTION}

Novel Coronavirus Disease 2019 (COVID-19) was initially announced in Wuhan city of Hubei State, China as pneumonia with unidentified origin on December 31, 2019 by World Health Organization (WHO) China Country Office (1). The outbreak immediately spread to countries out of China and WHO declared COVID-19 as pandemic on March 11, 2020 (1). COVID-19 has a severe course particularly in patients with chronic conditions or immunodeficiency and is associated with increased mortality (2). As vaccine trials are ongoing, new mutants of the virus are identified (3). Early diagnosis and treatment plays a key role in the management of COVID-19 viral infection with high transmission and fatality rates. WHO recommended Real Time-Polymerase Chain Reaction (RTPCR) as definitive method for detection of COVID-19, however it is not helpful for assessment of disease severity $(4,5)$. Several various biochemical and inflammatory markers were shown to be associated with the severity of COVID-19 (6).

Platelets (PLTs) play a substantial role in the recognition of injured endothelium, aggregation around site of injury, clot formation and also interaction with leukocytes for the initiation of inflammation (7-9). Certain proinflammatory molecules such as cytokines, chemokines and interleukins are stored in granules located in PLT and then released following activation. Mean platelet volume (MPV) value is an important indicator of PLT activation and has been shown to increase in states of infection and inflammation in previous reports (7-9). Moreover, increase in MPV values were shown to be associated with mortality in COVID-19 patients (10).

Red blood cell distribution width (RDW) is an indicator of heterogeneity in erythrocyte volume (11). Measurement of RDW is traditionally used in the differential diagnosis of anemia. Furthermore, RDW was shown to be a powerful predictor of morbidity and mortality in various patient populations (11). Increase in RDW value was shown to be correlated with the severity of COVID-19 (12).

Complete blood count tests, including RDW and MPV values, are easily accessible and measurable. They are also cheap routine blood tests providing rapid results for the evaluation of patients in emergency departments (ED). The present study aimed to investigate the use of RDW and MPV values for guidance in the decision of admitting patients with COVID-19 to ICUs or wards from the ED.

\section{MATERIALS AND METHODS}

The study was approved by the Ethical Committee of Ankara City Hospital (Date: 09/12/2020, No: E1-20-854).

The present study was conducted in Ankara City Hospital, a tertiary care healthcare facility located in Ankara, Turkey. The study was approved by the Ethical Committee of Ankara City Hospital. Retrospective analysis of patients presenting to the ED and admitted to ICU or wards after being diagnosed with COVID-19 via RT-PCR test or chest computed tomography findings consistent with COVID-19 pneumonia, between March 20, 2020 and April 10, 2020 was performed. All of the patients were over 18 years old. COVID-19 diagnosis of patients with chest CT findings compatible with COVID-19 was settled by consultation of the ED physician, radiologist, infectious disease specialists and ICU physicians. Patients diagnosed with COVID-19 via RT-PCR test or chest CT were excluded in the presence of chronic conditions (diabetes, myocardial infarction, etc.).

Patients were divided into two groups as patients admitted to ICU (Group 1) and those admitted to wards (Group $2)$. Group 1 included patients with severe pneumonia defined by WHO criteria (severe pneumonia adolescent or adult: fever or suspected respiratory infection, plus one of the following: respiratory rate $>30$ breaths/min; severe respiratory distress; or $\mathrm{SpO} 2 \leq 93 \%$ on room air (13)) and admitted to ICUs. Group 2 included patients admitted to wards who lack severe pneumonia criteria or recommendation for admission to ICU by an infectious diseases specialist.

Demographic characteristics, Complete Blood Count $(\mathrm{CBC})$ results, RDW and MPV values measured in the ED presentation of each patient were obtained from the hospital medical records system. The reference ranges in our hematology laboratory are as follows: Red Blood Cell (RBC), 4-5.65 x10^12/L; RDW, 11.5-16 \%; Hemoglobin $(\mathrm{Hb}), 12.5-17.2 \mathrm{~g} / \mathrm{dL}$; White Blood Cell (WBC) count: 3.6$10.5 \times 10^{\wedge} 9 / \mathrm{L}$; PLT, 160-400 x10^9/L; and MPV, 6-10 fL. RT-PCR detection kit (SARS-CoV-2 (2019-nCoV) qPCR Detection Kit, Bioeksen R\&D Technologies Ltd. Turkey) was used for COVID-19 diagnosis.

Components of CBC including RDW and MPV values of patients in both groups were evaluated.

\section{Statistical Analyses}

Continuous variables were presented as mean \pm standard deviation and median (interquartile quartiles). Normality 
was tested by calculation of skewness and kurtosis for all continuous variables. Unpaired t test was used to compare normally distributed continuous variables between two independent groups. Mann-Whitney $U$ test was used to test non-normally distributed continuous variables. A $p$ value of $<0.05$ was considered significant for all tests. Statistical Package for the Social Sciences (SPSS version 11.0, SPSS Inc., Chicago, IL, USA) was used.

\section{RESULTS}

During the study period, 271 patients were diagnosed with the COVID-19 disease and admitted to the hospital (128 patients to ICUs, 143 patients to wards). Of those, 144 patients $(53.1 \%)$ with chronic diseases were excluded from the study. The remaining 127 patients were evaluated. The number of male patients was $71(55.9 \%)$. Mean age was $46 \pm 17$ years in Group 1 and $41 \pm 14$ in Group 2, the difference was statistically significant (p: 0.013), (Table 1 ). The number of patients in Group 1 was 46 (36.2), and it was $81(63.7 \%)$ in Group 2. The number of discharged patients in the entire study population was $122(96.06 \%)$ and five patients died (3.9\%), all of which were patients admitted to ICUs (Group 1).

\section{Table 1. Study group characteristics}

\begin{tabular}{|c|c|c|c|}
\hline Parameters & $\begin{array}{l}\text { Group } 1 \\
\text { (Patients } \\
\text { admitted to } \\
\text { ICUs) }\end{array}$ & $\begin{array}{l}\text { Group } 2 \\
\text { (Patients } \\
\text { admitted to } \\
\text { wards) }\end{array}$ & $\mathbf{p}$ \\
\hline $\begin{array}{l}\text { Patient age } \\
\text { (years) }\end{array}$ & $46 \pm 17$ & $41 \pm 14$ & $0.013^{*}$ \\
\hline WBC (109/L) & 6.5 (9.6-4.6) & $6.35(7.6-5.2)$ & $0.031^{*}$ \\
\hline $\operatorname{RBC}(1012 / \mathrm{L})$ & $4.44 \pm 0.91$ & $4.89 \pm 0.48$ & $0.005^{*}$ \\
\hline $\mathrm{Hb}(\mathrm{g} / \mathrm{dL})$ & $13.3(14.8-11.1)$ & $14.1(15.2-13.2)$ & $0.006^{*}$ \\
\hline RDW (\%) & $15.9(14.6-16.7)$ & $13(14-12.6)$ & $<0.001^{*}$ \\
\hline $\begin{array}{l}\text { PLT count } \\
(109 / \mathrm{L})\end{array}$ & $175 \pm 90$ & $256 \pm 61$ & $<0.001^{*}$ \\
\hline MPV (fL) & $9.49 \pm 1.31$ & $8.10 \pm 0.93$ & $<0.001^{*}$ \\
\hline \multicolumn{4}{|c|}{$\begin{array}{l}\text { *p values indicate differences between ICU and non-ICU patients. } p \\
<0.05 \text { was considered statistically significant. Continuous variables } \\
\text { were presented as mean } \pm \text { standart deviation and median (interquartile } \\
\text { quartiles). Hb; Hemoglobin, ICU; Intensive Care Unit, MPV; Mean } \\
\text { Platelet Volume, PLT; Platelet, RBC; Red Blood Cell, RDW; Red Blood } \\
\text { Cell Distribution Width, WBC; White Blood Cell }\end{array}$} \\
\hline
\end{tabular}

WBC count in Group 1 (median: 6.5, range: 9.6-4.6) was higher than Group 2 (median: 6.35, range: 5.2-7.6), and it was statistically significant (p: 0.031). RBC count in Group
1 patients (mean: $4.44 \pm 0.91$ ) was lower than Group 2 (mean: $4.89 \pm 0.48$, p: 0.005$)$. $\mathrm{Hb}$ values were lower in Group 1 patients (median: 13.3, range: 11.1-14.8) than those in Group 2 (median: 14.1, range 13.2-15.2, p: 0.006) (Table 1).

RDW value in patients in Group 1 (median: 15.9, range: 14.6- 16.7) was significantly higher than patients in Group 2 (median: 13, range 12.6-14, $\mathrm{p}<0.001$ ). PLT count of patients in Group 1 (median: 15.9, range: 14.6-16.7) was lower than those in Group 2 (median: 13, range: 12.6-14, $\mathrm{p}<0.001$ ). MPV value in patients in Group 1 (mean $9.49 \pm$ 1.31) was higher than those in Group 2 (mean: $8.10 \pm 0.93$ $\mathrm{fL}, \mathrm{p}<0.001)$.

\section{DISCUSSION}

The severity of the disease in COVID-19 was shown to be associated with increasing age (14). In the present study patients admitted to ICUs (Group 1) were older than patients admited to wards (Group 2). However, mean age in both groups were younger than 50 years old. Median age of patients with severe and non-severe COVID-19 in the study by Zhenga et al. was similar with the present study (15). Despite the limited number of patients, it is widely accepted that COVID-19 is more common in middle-aged patients and the prognosis of the disease may be poor even in the absence of comorbid conditions in this patient population.

Moderate increase in WBC count values in patients with severe COVID-19 and a significant increase in WBC count values in patients who died due to COVID-19 disease were reported $(6,16)$. Similarly, the present study detected increased WBC count values in patients with severe COVID-19 who were admitted to ICUs than those admitted to wards.

RDW was shown to be a useful predictor of morbidity and mortality in a wide range of conditions including sepsis, pneumonia and other respiratory diseases $(6,11$, 17-19). Severe COVID-19 was shown to be associated with decreased $\mathrm{Hb}$ and hematocrit values while $\mathrm{RDW}$ was correlated with the severity of COVID-19 (10). On the other hand, another study pointed out a significant decrease in $\mathrm{Hb}$ related with increased pro-inflammatory cytokines in patients with severe and critical COVID-19 (20). In consistence with the above-mentioned findings, the present study also detected decreased $\mathrm{RBC}$ and $\mathrm{Hb}$ count and increased RDW in patients with COVID-19 
who were admitted to ICUs. Increase in RDW value was shown to be associated with the inflammatory response thus indicating decreased life turnover of blood cells in peripheral circulation and increased production in bone marrow (14, 21-23). Various pathophysiological mechanisms might have played a role in the decrease of $\mathrm{RBC}$ and $\mathrm{Hb}$ values while RDW is increased in severe COVID-19 cases including a gradual increase in anemia driven by immune injury leading to bone marrow suppression. Compensatory efforts including hyperplasia in erythrocyte cell series and release of immature red blood cells to peripheral circulation might have resulted in the RDW increase $(12,19)$.

Previous reports demonstrated that prognosis in patients with various diseases who require admission is associated with decreased PLT and increased MPV values (6, 7, 9, 24, 25).

Decreased PLT count was reported to be one of the most common laboratory findings in COVID-19 and associated with increased mortality and disease severity suggesting its use as a prognostic parameter $(15,20,26,25)$. Besides, MPV value is an important indicator of PLT activation that has been shown to increase in states of infection and inflammation in previous reports (7-9). Güçlü et al. reported that a decrease in the number of PLT and an increase in MPV were associated with mortality in COVID-19 patients (10). Furthermore, the present study also demonstrated decreased PLT and increased MPV values in COVID-19 patients admitted to ICU. PLTs play a dynamic role in COVID-19 as they also do in the inflammatory response to many viral diseases. Thus, one can use alterations in PLT parameters for escalating treatment strategies and decision making for admission to ICUs $(28,29)$.

Considering all the results obtained in the present study and referred previous studies, one can assume that increased RDW and MPV values in COVID-19 indicate initiation of PLT activation and severe inflammation in patients admitted to ICUs, even in their initial presentation to the ED.

The main limitation of the current study was the retrospective design in a single center. Besides, patients' data regarding the time period between symptom onset and ED presentation were missing. The sample size was not large enough due to the exclusion of patients with comorbid conditions, which may interact with $\mathrm{CBC}$ parameters.

In conclusion, RDW and MPV values were higher in those admitted to ICUs than patients admitted towards in patients with COVID-19. RDW and MPV values could be indicative of the severity of COVID-19 infection and the prognosis of the disease.

\section{Declarations}

The authors received no financial support for the research and/or authorship of this article. There is no conflict of interest.

The study was approved by the Ethical Committee of Ankara City Hospital (Date: 09/12/2020, No: E1-20-854).

\section{REFERENCES}

1. WHO. Rolling updates on coronavirus disease (COVID-19). Available at: https://www.who.int/emergencies/diseases/novelcoronavirus-2019/events-as-they-happen. Accessed February 26, 2021.

2. Sözen M, Karaköse M, Erayman İ, Demirbaş S, Teke T, Çölkesen F, et.al. Are patients with diabetes mellitus at increased risk of COVID-19 infection? Arch Curr Med Res 2021; 2(1):38-44.

3. Erganiş S, Bozdayı G. Virology, immunity and vaccine development of SARS-CoV-2. Arch Curr Med Res 2021; 2(1):05-13.

4. Tenda ED, Asaf MM. Diagnosing COVID-19: Did we miss anything? Acta Med Indones. 2020;52(1):1-4

5. Lippi G, Plebani M. The critical role of laboratory medicine during coronavirus disease 2019 (COVID-19) and other viral outbreaks. Clin Chem Lab Med. 2020;25;58(7):1063-1069.

6. Henry BM, De Oliveira MHS, BenoitS, Plebani M, Lippi G. Hematologic, biochemical and immune biomarker abnormalities associated with severe illness and mortality in coronavirus disease 2019 (COVID-19): a meta-analysis. Clin Chem Lab Med. 2020;25;58(7):1021-1028.

7. Speth C, Löffler J, Krappmann S, Lass-Flörl C, Rambach G. Platelets as immune cells in infectious diseases. Future Microbiol. 2013;8(11):1431-51.

8. Leader A, Pereg D, Lishner M. Are platelet volume indices of clinical use? A multidisciplinary review. Ann Med. 2012;44(8):805-16.

9. Korniluk A, Koper-Lenkiewicz OM, Kamińska J, Kemona H, DymickaPiekarska V. Mean Platelet Volume (MPV): New perspectives for an old marker in the course and prognosis of inflammatory conditions. Mediators Inflamm. 2019;17;2019:9213074.

10. Güçlü E, Kocayiğit H, Okan HD, Erkorkmaz U, Yürümez Y, Yaylacı S, et al. Effect of COVID-19 on platelet count and its indices. Rev Assoc Med Bras. 2020;66(8):1122-1127.

11. Salvagno GL, Sanchis-Gomar F, Picanza A, Lippi G. Red blood cell distribution width: A simple parameter with multiple clinical applications. Crit Rev Clin Lab Sci. 2015;52(2):86-105.

12. Henry BM, Benoit JL, Benoit S, Pulvino C, Berger BA, Olivera MHS, et al. Red blood cell distribution width (RDW) predicts COVID-19 severity: A prospective, observational study from the cincinnati SARS-CoV-2 emergency department cohort. Diagnostics (Basel). 2020;21;10(9):E618. 
13. WHO.Clinical management of severe acute respiratory infection(SARI) when COVID-19 disease is suspected: Interim guidance. Available at: https:/ / apps.who.int/iris/bitstream/handle/10665/331446/ WHO-2019-nCoV-clinical-2020.4-eng.pdf?sequence=1\&isAllowed=y . Accessed September 23, 2020.

14. Gong J, Ou J, Qiu X, Jie Y, Chen Y, Yuan L, et al. A tool for early prediction of severe coronavirus disease 2019 (COVID-19): A multicenter study using the risk nomogram in Wuhan and Guangdong, China. Clin Infect Dis. 2020;28;71(15):833-840.

15. Zheng Y, Zhang Y, Chi H, Chen S, Peng M, Luo L, et al. The hemocyte counts as a potential biomarker for predicting disease progression in COVID-19: a retrospective study. Clin Chem Lab Med. 2020;25;58(7):1106-1115.

16. Skevaki C, Fragkou PC, Cheng C, Xie M, Renz H. Laboratory characteristics of patients infected with the novel SARS-CoV-2 virus. J Infect. 2020;81(2):205-212.

17. Topaz G, Kitay-Cohen Y, Peled L, Gharra W, Kaminer K, Eitan M, et al. The association between red cell distribution width and poor outcomes in hospitalized patients with influenza. J Crit Care. 2017;41:166-169.

18. Braun E, Domany E, Kenig Y, Mazor Y, Makhoul BF, Azzam ZS. Elevated red cell distribution width predicts poor outcome in young patients with community acquired pneumonia. Crit Care. 2011;11;15(4):R194.

19. Kim CH, Park JT, Kim EJ, Han JH, Han JS, Choi JY, et al. An increase in red blood cell distribution width from baseline predicts mortality in patients with severe sepsis or septic shock. Critical Care 2013;17:R282.

20. Pourbagheri-Sigaroodi A, Bashash D, Fateh F, Abolghasemi H. Laboratory findings in COVID-19 diagnosis and prognosis. Clin Chim Acta. 2020 Aug 14;510:475-482.

21. Semba RD, Patel KV, Ferrucci L, Sun K, Roy CN, Guralnik JM, et al. Serum antioxidants and inflammation predict red cell distribution width in older women: the Women's Health and Aging Study I. Clin Nutr. 2010;29(5):600-4.

22. Scharte M, Fink MP. Red blood cell physiology in critical illness. Crit Care Med. 2003;31(12 Suppl):S651-7.

23. Bazick HS, Chang D, Mahadevappa K, Gibbons FK, Christopher KB. Red cell distribution width and all-cause mortality in critically ill patients. Crit Care Med. 2011;39(8):1913-21.

24. Lippi G, Plebani M, Henry BM. Thrombocytopenia is associated with severe coronavirus disease 2019 (COVID-19) infections: A metaanalysis. Clin Chim Acta. 2020;506:145-148.

25. Karadag-Oncel E, Ozsurekci Y, Kara A, Karahan S, Cengiz AB, Ceyhan M. The value of mean platelet volume in the determination of community acquired pneumonia in children. Ital J Pediatr. 2013;8;39:16.

26. Kermali M, Khalsa RK, Pillai K, Ismail Z, Harky A. The role of biomarkers in diagnosis of COVID-19 - A systematic review. Life Sci. 2020;1;254:117788.

27. Bao C, Tao X, Cui W, Yi B, Pan T, Young KH, et al. W. SARS-CoV-2 induced thrombocytopenia as an important biomarker significantly correlated with abnormal coagulation function, increased intravascular blood clot risk and mortality in COVID-19 patients. Exp Hematol Oncol. 2020;17;9:16.

28. Hottz ED, Bozza FA, Bozza PT. platelets in immune response to virus and immunopathology of viral infections. Front Med (Lausanne). 2018;30;5:121.

29. Salamanna F, Maglio M, Landini MP, Fini M. Platelet functions and activities as potential hematologic parameters related to Coronavirus Disease 2019 (COVID-19). Platelets. 2020;3;31(5):627-632. 